\title{
Simplistic and complex thought in medicine: the rationale for a person-centered care model as a medical revolution
}

This article was published in the following Dove Press journal:

Patient Preference and Adherence

5 April 2016

Number of times this article has been viewed

\author{
Gérard Reach ${ }^{1,2}$ \\ 'Department of Endocrinology, \\ Diabetes and Metabolic Diseases, \\ Avicenne Hospital AP-HP, ${ }^{2}$ EA 34I2, \\ Centre de Recherche en Nutrition \\ Humaine Ile-de-France (CRNH-IDF), \\ Paris 13 University, Sorbonne Paris \\ Cité, Bobigny, France
}

Abstract: According to the concept developed by Thomas Kuhn, a scientific revolution occurs when scientists encounter a crisis due to the observation of anomalies that cannot be explained by the generally accepted paradigm within which scientific progress has thereto been made: a scientific revolution can therefore be described as a change in paradigm aimed at solving a crisis. Described herein is an application of this concept to the medical realm, starting from the reflection that during the past decades, the medical community has encountered two anomalies that, by their frequency and consequences, represent a crisis in the system, as they deeply jeopardize the efficiency of care: nonadherence of patients who do not follow the prescriptions of their doctors, and clinical inertia of doctors who do not comply with good practice guidelines. It is proposed that these phenomena are caused by a contrast between, on the one hand, the complex thought of patients and doctors that sometimes escapes rationalization, and on the other hand, the simplification imposed by the current paradigm of medicine dominated by the technical rationality of evidence-based medicine. It is suggested therefore that this crisis must provoke a change in paradigm, inventing a new model of care defined by an ability to take again into account, on an individual basis, the complex thought of patients and doctors. If this overall analysis is correct, such a person-centered care model should represent a solution to the two problems of patients' nonadherence and doctors' clinical inertia, as it tackles their cause. These considerations may have important implications for the teaching and the practice of medicine.

Keywords: person-centered medicine, nonadherence, clinical inertia, complexity, abduction, paradigm, revolution, evidence-based medicine

\section{Introduction}

Our work is an incessant collection of evidence, weighing of evidence, and judging upon the evidence, and we have to learn early to make large allowances for our own frailty, and still larger for the weaknesses, often involuntary, of our patients. [Sir William Osler, 1907] ${ }^{1}$

Patient adherence is generally considered a major issue in contemporary medicine. The concept was described in 1979 by Sackett ${ }^{2}$ under the term "compliance", as the extent to which the patient's behavior matches the prescriber's recommendations. Today, the term "adherence" is preferred, as it has a more active connotation. In 2003, the World Health Organization published a report recognizing the critical importance of nonadherence due to its major deleterious impact on the efficiency of care. ${ }^{3}$ Indeed, the magnitude of this phenomenon cannot be overlooked; for instance, consider the fact that whatever the medication, the ratio of the total day's supply of medication that was dispensed, divided by the number of days of the evaluation period, is only $\sim 60 \% 2$ years after the initiation

\footnotetext{
Correspondence: Gérard Reach Department of Endocrinology, Diabetes and Metabolic Diseases, Avicenne Hospital AP-HP, I 25 Rue de Stalingrad, Bobigny 93000, France

Tel +33 | 48955 I 58

Fax +33 | 48955560

Email gerard.reach@aphp.fr
}

(c) (5) ( 2016 Reach. This work is published and licensed by Dove Medical Press Limited. The full terms of this license are available at https://www.dovepress.com/terms.php

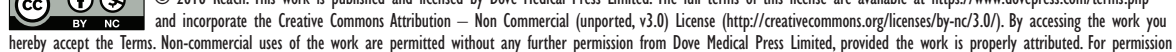
for commercial use of this work, please see paragraphs 4.2 and 5 of our Terms (https://www.dovepress.com/terms.php). 
of therapy. ${ }^{4}$ There is a second issue that currently jeopardizes the proficiency of care: clinical inertia, a concept described by Phillips et $\mathrm{al}^{5}$ in 2001, based on the observation that physicians often do not follow current good practice guidelines that they know. This is also a frequent phenomenon, observed in $~ 50 \%$ of medical visits. ${ }^{6}$ Both patients' nonadherence and doctors' clinical inertia cause a huge burden in terms of health expenditure, estimated in billions of dollars, ${ }^{7,8}$ and these therefore represent a major subject of concern for health authorities.

The two phenomena share a common characteristic: at first glance, they are surprising. How is it possible that, so frequently, patients do not follow a medical prescription, while they often know that this behavior is detrimental to their health? How is it possible that, so frequently, doctors do not comply with good practice guidelines when they are supposed to propose the best treatments to their patients? In this article, it is proposed considering these phenomena as anomalies that, due to their frequency and potential consequences, create a real crisis in contemporary medicine.

The terms "anomalies" and "crisis" refer to the description by Thomas Kuhn $n^{9}$ of the structure of scientific revolutions. In the realm of science, a revolution occurs when scientists encounter a crisis caused by the observation of anomalies that cannot be explained by the generally accepted paradigm within which scientific progress has thereto been made: a scientific revolution can therefore be described as a change in paradigm aimed at solving a crisis. It is proposed herein 1) that patients' nonadherence and doctors' clinical inertia are surprising, ie, are seen as anomalies, because they are considered in the framework of a practice largely dominated by the technical rationality of the evidence-based medicine (EBM) paradigm; 2) that the advent of this paradigm at the end of the past century imposed a simplification that contrasts with the complex thought of patients and doctors, which sometimes escapes rationalization; 3) that this contrast caused patients' nonadherence and doctors' clinical inertia appearing as the symptoms of a crisis. It is proposed therefore that, 4 ) if there is a crisis, a change in paradigm is needed, replacing the EBM model with a new model of care; and finally, 5) that a person-centered model may play such a role if it is defined by its ability to take into account the complex thought of patients and doctors. Such a conception of the person-centered model of care would have major implications for the practice and teaching of medicine as well as for defining new research topics in the field of health care.

The aims of this article are therefore to describe the contrast that exists between the simplification trend of the EBM model paradigm on the one hand, and on the other hand, the complex thought of patients and doctors, which is described herein as well as to show how a person-centered model of care may take into account this complex thought. But first, it is shown how an abduction-based approach makes it possible to tackle the surprise caused by the observation of patients' nonadherence and doctors' clinical inertia.

\section{The logic of abduction: a way to explain surprising phenomena}

\author{
The surprising fact, $\mathrm{C}$, is observed; \\ But if A were true, $\mathrm{C}$ would be a matter of course. \\ Hence, there is reason to suspect that $\mathrm{A}$ is true. \\ [Charles S Peirce, CP 5.189] ${ }^{10}$
}

Abduction was discovered by the American philosopher Charles Sanders Peirce (1839-1914). Peirce claimed that abduction "is the process of forming explanatory hypotheses [such as A, above]. It is the only logical operation which introduces any new idea." [CP 5.172 $]^{10}$

According to Jaime Nubiola, ${ }^{11}$ who defined Peirce's abduction as a logic of surprise,

\begin{abstract}
A "surprising" fact requires $[\ldots]$ an explanation. An explanation makes the facts rational, that is, it enables the acquisition of a belief that explains the fact, rendering it reasonable. When the phenomenon is reasonable it is no longer surprising.
\end{abstract}

Nubiola quoted Peirce's own words:

What an explanation of a phenomenon does is to supply a proposition which, if it had been known to be true before the phenomenon presented itself, would have rendered that phenomenon predictable, if not with certainty, at least as something very likely to occur. It thus renders that phenomenon rational - that is, makes it a logical consequence, necessary or probable. [CP 7.192 $]^{10}$

However, it is important to realize that abduction represents a powerful logic operation aimed at finding explanations to surprising phenomena, but that their value must be tested by verification procedures. Claudine Tiercelin ${ }^{12,13}$ noticed that Peirce himself considered that abduction is:

A process of thought capable of producing no conclusion more definite than a conjecture. [EP 2.232]. Abduction merely suggests that something may be, [so that] its only justification is that from its suggestion, deduction can draw a prediction which can be tested by induction. [EP 2.216] [Thus, one must indeed always remember] that any 
hypothesis, therefore, may be admissible, in the absence of any special reason to the contrary, provided it be capable of experimental verification, and only in so far as it is capable of such verification. This is approximately the doctrine of pragmatism. [EP 2.235] $]^{14}$

According to Tiercelin, abduction should be seen, in Peirce's mind, as an inference, not to a strong explanation, or even to "the best explanation," but at least to a good explanation, the choice of which among a number of possibilities is performed within a solid background of previous knowledge. Abducted hypotheses must therefore be tested before being adopted (and it may be that, after the test, one of the hypotheses is selected as "the best explanation"). ${ }^{13}$ Thus, due to the relative weak strength of abduction-based hypotheses, not any idea is eligible to be chosen as an explanation, and Sami Paavola ${ }^{15}$ proposed that abduction obeys a strategy:

So if I am a researcher looking for a good explanatory hypothesis for some anomalous phenomenon, I can (and must) try to constrain and guide my search by taking into account that my explanation must explain or at least be consistent with, most other clues and information that I have available concerning the subject matter. And I try to anticipate that my explanation has some chance of survival in subsequent tests and assessments. Usually I must also take into account that the proposed explanation should not be totally unconvincing, or if it seems to be that, I should have a good further explanation for why this explanation still deserves attention. So, I should have an explanation for my explanation.

This article aims at proposing as an explanatory hypothesis [A] to the two surprising phenomena of patients' nonadherence and doctors' clinical inertia [C] that they are surprising in the framework of the current medical model of care that is largely dominated by EBM. As shown in the following section, EBM imposes a simplification that contrasts with the complex thought of patients and doctors. The explanatory hypothesis [A] for understanding [C] can therefore be formulated in Peirce's terminology: "if A were true, $\mathrm{C}$ would be a matter of course," where [A] denotes: "the contrast between the simplification imposed by EBM and the complex thought of patients and doctors causes patients' nonadherence and doctors' clinical inertia"; and [C] denotes: "patients' nonadherence and doctors' clinical inertia are possible".

Thus, in this abduction-based logic, a new medical model that would take into account the patients' and doctors' complex thought should be well suited to fight against patients' nonadherence and doctors' clinical inertia. It is proposed that this ability is (or should be) the precise aim of a person-centered model of care and that the invention of this model in contemporary medicine ${ }^{16}$ may have therefore proceeded from an abduction-based logic used to understand the two phenomena of patients' nonadherence and doctors' clinical inertia (Figure 1).

Moreover, due to its importance in contemporary medicine, EBM represents its current paradigm. Although Peirce's abduction is never mentioned in Kuhn's The Structure of Scientific Revolutions, ${ }^{9}$ it is tempting to propose that this abduction-based discovery of a person-centered model of care may currently lead to a change in paradigm having the structure of a revolution occurring here in the medical realm. Note that this would be a revolution in the domain of practice, while scientific revolutions, described by Kuhn, ${ }^{9}$ are revolutions in the domain of knowledge.

\section{Simplification in EBM and the complex thought of patients and doctors}

In this section, it is emphasized that the current medical model of care imposes simplification in two major ways. First, this simplifcation assumes that patients and doctors are rational beings who seek to optimize their self-interest: the simplifying method of contemporary medicine ignores the complexity, which often escapes rationalization, of the individual decisions of doctors and patients; second, it assumes that it is scientifically possible to base best practice guidelines on EBM, which relies on the often-irreproachable results of randomized clinical trials: it is shown that the use of the scientific method, which rests on the use of statistical data, is well suited to generate knowledge, but that both the generation of best practice guidelines and their real application from statistical data are more problematic.

\section{First criticism: EBM ignores the complex thought of patients and doctors}

In one of his writings devoted to complex thought, French sociologist Edgar Morin ${ }^{17}$ recognized that:

The idea of a universe of objective facts, purged of any value judgments, of any subjective deformations, thanks to the experimental method and the procedures of verification, allowed the extraordinary development of modern science.

He added, however, that:

A rationalization which locks up reality in a coherent but partial and unilateral system of ideas, and which ignores 


\section{Surprising $\longrightarrow$ Explanatory observations hypothesis}

$\begin{array}{ll} & \\ & \begin{array}{l}\text { The contrast between } \\ \text { the simplification }\end{array} \\ \begin{array}{l}\text { Patient's nonadherence } \\ \text { (PNA) }\end{array} & \begin{array}{l}\text { imposed by EBM and } \\ \text { the complex thought of } \\ \text { patients and doctors } \\ \text { causes PNA and DCl }\end{array} \\ \begin{array}{l}\text { Doctors' clinical inertia } \\ \text { (DCI) }\end{array} & \begin{array}{l}\text { PNA and DCl are } \\ \text { puzzling in the } \\ \text { framework of EBM's } \\ \text { rationality }\end{array}\end{array}$

1. Human behaviors are complex and not only rational

2. EBM stems from positivist rationality. This is appropriate for generating knowledge, but inappropriate for proposing guidelines (differences between clinical trials and the clinical context of care)

3 . There is a confusion between epistemic and practical aspects of EBM; EBM-derived guidelines are mainly useful for teaching medicine (corpus of knowledge)
New model

Validation of hypothesis

Person-centered model for practical medicine defined by its ability to take into account the complexity of human thought

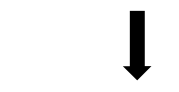

1. First step: individualized medicine and guidelines, leading to personalized medicine

2. Training doctors in person-centered medicine through a teaching of

humanistic medicine

(complex thought)

\author{
New hypotheses \\ on the mechanisms \\ of care, generated \\ from clinicians' intuitions \\ and qualitative studies

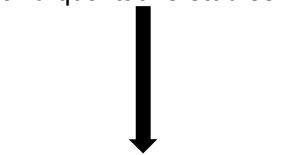 \\ Design of interventions \\ to improve patients' \\ adherence and to fight \\ against doctors' clinical \\ inertia: quantitative studies \\ (EBM)
}

Figure I From surprising observations to a practical, person-centered model of medicine: an abduction-based approach.

Notes: Abduction: on the basis of arguments (background), surprising observations lead to the proposal of an explanatory hypothesis that, if it were true, would make the observations understandable. This hypothesis leads to a new model, making it possible to design empirical tests aimed to validate the hypothesis. A validation of the initial hypothesis may lead to a change in paradigm: replacement of the EBM-based paradigm of medicine by a person-centered model of care.

Abbreviation: EBM, evidence-based medicine.

that part of reality is irrationalizable, and that rationality has

the role of dialoguing with the irrationalizable, represents

a pathology of reason [translation mine].

This article argues that this description of the evolution of contemporary science is applicable to medicine, leading to a "pathology of reason" revealed by two symptoms that at first glance seem puzzling or even irrational: patients' nonadherence and doctors' clinical inertia. They are puzzling because they represent anomalies of a "coherent but partial and unilateral system of ideas", putting it into a crisis.

Indeed, patients and doctors, as any human beings, do not base their decisions only on pure "rational" arguments because of the uncertainty associated with the result of any action and because of the complexity of the human mind. ${ }^{18-20}$ They may have an aversion for losses, which is greater than their attraction for gains; ${ }^{21}$ they may prefer a smaller but more immediate reward (eg, tasty but unhealthy foods) to greater long-term benefit (eg, the preservation of health); ${ }^{22}$ they sometimes have a short temporal horizon; ${ }^{23}$ finally, their cognition uses powerful mental mechanisms or heuristics ${ }^{24}$ that make it possible to reason rapidly, ${ }^{25}$ and they are under the influence of emotions. ${ }^{26,27}$ However, whereas empathy is prized in the physician-patient relationship, there are no emotions in $\mathrm{EBM}^{28}$

Heuristics and emotions may have evolved in the human mind because, at some previous time, they offered a selective advantage, allowing survival in a complex environment. But in medicine, they may have a dark side: they can lead patients to become unduly risk-averse and thereby make decisions that constitute nonadherence. The same holds true for doctors who may prefer to observe the "primum non nocere" rule and thus behave in an inert way. Both doctors and patients may indeed prefer making errors of omission and suffer the results of what they did not do over errors of commission in which something bad happens because of what they did. Nonadherence and clinical inertia, as they usually embody preferences for the status quo, are primarily errors of omission and could therefore represent the toll that we pay for the presence of heuristics and emotions in our mental lives.

Thus, best practice guidelines, when doctors know them, are only a part of their clinical decision making. In addition to the rational arguments, doctors also use heuristics that permit quicker decisions and are frequently sensitive to emotions such as "gut feelings". ${ }^{29}$ Instead of guidelines, doctors may use "mindlines", ${ }^{30}$ ie, mental combinations of information 
developed based on different sources: certainly the guidelines themselves, but also what they learned during their studies and their training, their own clinical experience, discussions they have had with their local colleagues or those they encounter during postgraduate training sessions or conventions, their interactions with patients and the pharmaceutical industry, and finally what "opinion leaders" tell them.

Most importantly, the physician tries to have a holistic vision of the situation. Ideally, the doctor functions as a "master", who, following the description of Stuart E Dreyfus and Hubert L Dreyfus, ${ }^{31}$ no longer uses the guidelines that enabled him or her to "play" at the outset. These authors use as an illustration of how people learn to play chess: initial instruction (guidelines) gets a beginner started, but through experience, the player begins to recognize situations in a more holistic way and make decisions by relying on what one often calls "intuition". This illustration suggests that best practice guidelines are necessary, but principally at the beginning of the practice and, therefore, have principally a major teaching interest. We must remember that the very first paper using the words "evidence-based medicine" in its title presented EBM as "a new approach to teaching the practice of medicine". ${ }^{32}$ These observations on the holistic appreciation of the context may also apply to the patient's consideration of whether to follow a doctor's recommendations. ${ }^{33}$

To summarize, the mode of reasoning used by patients and doctors does not always rely on the rationality simplistically assumed by practice guidelines (recommendations of health authorities to doctors) or by medical advice (recommendations of doctors to patients). Within the framework of a purely rational model of medicine, disease, doctors, and patients, nonadherence and clinical inertia appear surprising. But our surprise disappears once we admit that these behaviors reveal that patients and doctors are human beings endowed with complex thought, as defined by Edgar Morin. ${ }^{17}$

\section{Second criticism: a confusion between the epistemic and practical aspects of EBM}

Let us create by randomization two groups of patients, the characteristics of whom at the baseline (calculated means) are identical. Undoubtedly, the scientific results of a trial comparing the effect of a medication and of a placebo will be objective (because the patients as individual subjects have disappeared from view). But as pointed out very early by Feinstein and Horwitz, ${ }^{34}$ one has overlooked many of the subtler or fuzzier aspects of the data: the specific symptoms, the patient's psychological profile, the difficulties of ensuring adherence in each individual case, and the patient's wishes. In addition, individuals differ according to their genetic background. For these reasons, when a treatment is prescribed according to a generic guideline derived from randomized controlled trials, some patients respond well to it and some do not; furthermore, some patients experience side effects and others do not due to the variability of living phenomena. An aim of large clinical trials is to describe this variability and to generate statistical data, ie, knowledge. However, the statistical method, which is the very basis of EBM, is a simplifying method, because it eliminates complexity from reality by trying to eliminate variability through the calculation of means and the use of randomization procedures. For this reason, any prediction from that knowledge is only statistical, and any guideline derived from it has only a relative value.

For instance, we could design a statistical study and show that most people stop when the light is red (knowledge). However, this knowledge does not imply that "Jeremy" will stop at "a particular intersection" because the light is red. Jeremy never stops at red lights. However, on that day, Jeremy stopped because the corner bakery was open, and he wanted to buy a croissant. ${ }^{35}$ This example is relevant for the issue addressed by this article, because, similar to Jeremy, patients and doctors - during their encounters act as individuals having their reasons for doing what they do. ${ }^{19,20}$ Of course, observation of an individual case has its limits as an explanatory mode. For example, the alcoholism of parents could conceivably explain either the alcoholism or the sobriety of their children; according to Jon Elster, ${ }^{36}$ such a "mechanism", described as something intermediary between a law and a simple description, makes it possible to explain but not to predict.

This last remark points out the limits of using knowledge derived from statistical data. In sum, there is a confusion between two aspects, epistemic (generation of knowledge) and practical (production of guidelines), of EBM, which has already been underscored by Saarni and Gylling. ${ }^{37}$ Indeed, clinical trials are designed as a scientific experience: some patients are included and others excluded, and when included patients do not persist, one says that they "drop out"; doctors are transformed into investigators, and they are rarely inert; in contrast, in the real world of medical practice and health care, one often observes doctors' clinical inertia and patients' nonadherence, which is much more complex than merely "dropping out."

This confusion indeed ignores the difference between science and practice. In clinical trials, one wants to answer 
a question that has been determined a priori (incidentally, a clinical trial is nothing but the verification of a hypothesis often generated by abduction), and positivist science aims at answering such questions and thereby generating knowledge, mainly in the form of statistical data. However, simplification is needed: the patients studied lose their status as subjects and become simple objects of research. In the world of practice, doctors and patients are subjects who do not ask questions or problems that may be answered or solved through a technical rationality taking its roots in positivism, but they have to make a decision in an undetermined and complex situation, as shown by Donald A Schön ${ }^{38}$ in his The Reflective Practitioner: How Professionals Think in Action. According to Schön,

In real-world practice, problems do not present themselves to the practitioner as givens [...] In order to convert a problematic situation to a problem, a practitioner must [...] make sense of an uncertain situation that initially makes no sense.

Setting, not solving, the problem is the real difficulty. He cites what one of his physician friends told him: " 85 percent of the problems a doctor sees in his office are not in the book." Formulation of the problem by the practitioner falls under, not a "Technical Rationality", but rather what he calls "Reflection-in-Action": this is that know-how which the practitioner is not always able to describe and which is based on the inventive improvisation learned in practice.

It is proposed herein that it is this confusion between the two realms of medical science and clinical practice that not only renders patients' nonadherence and doctors' clinical inertia surprising but also causes them, generating a crisis. Another model is therefore needed, taking into account the perspective of singular people having subjective reasons s $^{19,20}$ for doing what they do.

\section{Operational definition of a new model suitable for improving the efficiency of care}

From what precedes, a person-centered model of care may play this role, considering that it takes again into account the complex thought of patients and doctors: Descartes defined in his Theory of Passions, apart from any medical context, the "patient" and the "agent" as beings to whom and by whom events occur. A "person"-centered model should be defined as a model that tries to see the person who enters into the process of care due to a particular event (the onset of a disease), not as a "patient" or even as an "agent," but as a being who remains "a person", defined as a being endowed with reflectivity, having preferences, ${ }^{39-41}$ a history, ${ }^{42}$ and a psychological continuity ${ }^{43}$ - in a nutshell, having a complex thought.

This operational definition of a person-centered model, proposed herein, has concrete implications for training doctors (Figure 1). In addition to teaching scientific medicine, largely based on the epistemic corpus of EBM (knowledge) and where good practice guidelines are essentially presented as guiding rules that teach them during their training to solve theoretical clinical cases ${ }^{32}$ and that they will be able to use at the beginning of their practice or when they will be confronted by a disease with which they are not familiar, they should be tutored in the practice of person-centered medicine. First, in what we typically call the "interview" of the patient, it would be useful to teach students to consider not only the patient's "past history", but also his or her projects or goals. Second, a medicine centered on the person requires a skillful conversation $^{44}$ on preferences, ${ }^{45,46}$ ie, on values. ${ }^{47}$ Third, in the course of this conversation, they should be taught how to create a climate of trust, ${ }^{48}$ whereby both the patient and the doctor act as persons; at the end of the encounter, to ask "What else?"49 and invite the person to disclose the complexity of his or her life and concerns. In sum, when looking at the being seated opposite them, doctors must learn to resist the temptation to see a "patient" or, worse, "a disease" but must, rather, learn to see a person: to become more able to see the person beyond the patient, doctors could be trained to look at each person's face and recognize its uniqueness. In antiquity, one thought that the word "person" comes from "persona", the ancient theater mask that made it possible for performers to amplify the voice ("per/sonare") and for viewers to recognize the character at the same time.

This also has implications for further research (Figure 1). One may fear that an individualistic model of care leads to scientific indemonstrability because, essentially, it precludes any statistical approach. In fact, we saw earlier that in an abduction-based logic, the explanatory hypothesis requires a validation. Thus, this need for a "verification" of our explanatory hypothesis (namely, "the contrast between the simplification imposed by EBM and the complex thought of patients and doctors causes patients' nonadherence and doctors' clinical inertia") is clearly shown in Figure 1: the new personcentered model of care, generated from the hypothesis, makes it possible to formulate further hypotheses on the mechanisms of care in general, or specifically with regard to nonadherence and clinical inertia. These hypotheses can derive from clinicians' psychological intuition (eg, because a person is defined by his or her psychological continuity, ${ }^{43}$ teaching 
students to ask patients about their projects during the medical interview should improve the quality of the patient-doctor relationship and thereby improve subsequently the rate of adherence) or from empirical qualitative studies (eg, asking doctors why they do not follow guidelines). Next, because it is considered useful to improve patients' adherence ${ }^{3}$ and to reduce doctors' tendency toward clinical inertia, ${ }^{50}$ these hypotheses can lead to the design of interventions that could be evaluated scientifically, this time by quantitative studies. If the explanatory hypothesis is true, these interventions should be able to improve patients' adherence and limit doctors' clinical inertia: back to EBM.

\section{The person-centered model of care in a historical perspective}

A person-centered care model makes it possible to design a real synthesis between practice and ethics, being a solution to the frequent dilemma between the ethical principles of beneficence/nonmaleficence and autonomy. ${ }^{51}$ Historically, 1) the principle of autonomy was introduced in bioethics by Beauchamp and Childress ${ }^{52}$ in their seminal book Principles of Biomedical Ethics. 1st ed. published in 1979; 2) the concept of EBM was anticipated by Cochrane ${ }^{53}$ in 1972; 3 ) the same year, Miller and Goldstein ${ }^{54}$ showed that patient education resulted in a decrease in the rate of amputation and hospitalization due to ketoacidosis in diabetic patients; and 4) Engel ${ }^{55}$ proposed the biopsychosocial model of diseases in 1977. However, these four conceptual inventions in medicine, which seem to have occurred almost simultaneously, led rapidly to two disappointments: 1) the concept of noncompliance was established by Sackett ${ }^{2}$ in 1979; and 2) Phillips et $\mathrm{al}^{5}$ coined the keyword "clinical inertia" in 2001, based on the strong evidence that the publication of best practice guidelines had actually a weak impact on physicians' behaviors. ${ }^{56,57}$ In this historical perspective, the invention of a person-centered care model, ${ }^{16}$ the roots of which are described herein, has not only an ethical virtue. It seems actually to represent the end point of a long epistemological transition.

In general, complexity resists simplification: the construction of best practice guidelines based on statistics carried the risk of producing generic guidance that, when addressed to patients in an indistinct and unindividualized way that sometimes ignores patients' preferences, ${ }^{47}$ appears to be the cause of the two seemingly surprising phenomena of patients' nonadherence and doctors' clinical inertia, both of which jeopardize the effectiveness of care. The principle of individualized guidelines recently proposed in diabetes care ${ }^{58}$ (both the glycated hemoglobin [HbAlc] target and the choice of second-line therapy are customized to the characteristics of the patient) tries to palliate the inability of good practice guidelines to be universal and seems to move in the direction proposed in this article. It may therefore represent a cornerstone in the history of EBM, ${ }^{59}$ even if "individualized guidelines" represent only an approach to "personalized" medicine using patients' categorization according to criteria, not yet a true "person-centered" model of care. For sure, the founding fathers of EBM defined it as "the conscientious, explicit, and judicious use of current best evidence in making decisions about the care of individual patients," ${ }^{60}$ and they always pointed out the need to take into account not only "the science" but also the patient's characteristics and wishes. ${ }^{61}$ However, the fact that a proposal of "individualized" guidelines today seems novel proves that this initial definition of EBM has been forgotten.

\section{Conclusion: a revolution, or a return to the ancient?}

Actually, the "invention" of person-centered care may be a rediscovery: back in 1882, the Viennese professor of internal medicine Hermann Nothnagel (1841-1905) said, "I repeat once again, medicine is about treating sick people, and not diseases"; Sir William Osler (1849-1919) professed that "the good physician treats the patient, the great physician treats the person"; and in the oath of Maimonides (1135/8-1204), one finds: "May I never see in the patient anything but a fellow creature in pain." It is proposed that the simplifying confusion between the epistemic and practical aspects of EBM eclipsed this humanistic view of medicine, and that patients and doctors tried, more or less consciously, to resist this loss by expressing nonadherence and clinical inertia, respectively.

This article shows that using the logic of abduction for understanding these apparently puzzling phenomena leads naturally to a person-centered model, whereby medicine can be rediscovered as an art of complexity. It proposes that this model can be seen as a synthesis of successive attempts - the patient-centered biopsychosocial model, ${ }^{55}$ the deliberative model ${ }^{45}$ leading to shared decision-making, ${ }^{62}$ preferencebased medicine, ${ }^{46}$ and recently, the preference-sensitive guidelines ${ }^{47}$ aimed at returning to the sources of medicine. Even if it is a return to the ancient, this move may represent a change in paradigm that will be, as always, slow and progressive, and whose acceptance will certainly meet resistance. ${ }^{9}$ However, it may represent the only way to overcome the two barriers of patients' nonadherence and doctors' clinical 
inertia that currently jeopardize the efficiency of care, considering that it tackles their very cause.

This article has aimed at justifying the invention or the revival of a person-centered model of care as a medical revolution. In a companion article, ${ }^{63}$ the ethical conditions of its implementation shall be discussed.

\section{Acknowledgment}

The author wishes to express his deep gratitude to Pascal Engel, Bernard Baertschi, Sadek Béloucif, Pierre-Jean Lefèbvre, and Alain Krivitzky for fruitful discussions and advice concerning this manuscript.

\section{Disclosure}

The author reports no conflicts of interest in this work.

\section{References}

1. Osler W. The evolution of internal medicine. Modern Medicine: Its Theory and Practice. Philadelphia: Lea Brothers and Co.; 1907.

2. Sackett DL. Introduction. In: Sackett DL, Haynes RB, editors. Compliance with Therapeutic Regimens. Baltimore: The John Hopkins University Press; 1979:1-6.

3. WHO Report. Adherence to Long-Term Therapies. Evidence for Action. Geneva: WHO; 2003.

4. Curtis JR, Xi J, Westfall AO, et al. Improving the prediction of medication compliance: the example of bisphosphonates for osteoporosis. Med Care. 2009;47:334-341.

5. Phillips LS, Branch WT, Cook CB, et al. Clinical inertia. Ann Intern Med. 2001;135:825-834.

6. Okonofua EC, Simpson KN, Jesri A, Rehman SU, Durkalski VL, Egan BM. Therapeutic inertia is an impediment to achieving the Healthy People 2010 blood pressure control goals. Hypertension. 2006; 47:345-351

7. Lee WC, Balu S, Cobden D, Joshi AV, Pashos CL. Prevalence and economic consequences of medication adherence in diabetes: a systematic literature review. Manag Care Interface. 2006;19:31-41.

8. O'Connor PJ, Sperl-Hillen JAM, Johnson PE, Rush WA, Biltz G. Clinical inertia and outpatient medical errors. In: Henriksen K, Battles JB, Marks ES, Lewin DI, editors. Advances in Patient Safety: From Research to Implementation (Volume 2: Concepts and Methodology). Rockville, MD: Agency for Healthcare Research and Quality (US); 2005:293-308.

9. Kuhn T. The Structure of Scientific Revolutions. 2nd ed. Chicago: University of Chicago Press; 1970.

10. Peirce CS. In: Hartshorne C. Weiss P, Burks AW, editors. The Collected Papers of Charles Sanders Peirce. Vol. I-VIII. Cambridge: Harvard University Press; 1931-1966. Reference to Peirce's papers are designated $\mathrm{CP}$ followed by volume and paragraph number.

11. Nubiola J. Abduction, a logic of surprise. Semiotica. 2005;153:117-130.

12. Tiercelin C. Abduction and the semiotics of perception. Semiotica. 2005; 153:389-412.

13. Tiercelin C. Le Ciment des Choses. Petit traité de métaphysique scientifique réaliste. Paris, Ithaque: Sciences et Métaphysiques; 2011.

14. Peirce Edition Project. The Essential Peirce: Selected Philosophical Writings, Vol 2 (1893-1913). Bloomington: Indiana University Press; 1998. Reference to vol 2 of Essential Peirce are designated EP 2.

15. Paavola S. Abduction as a logic and methodology of discovery: the importance of strategies. Found Sci. 2004;9:267-283.

16. Entwistle VA, Watt IS. Treating patients as persons: a capabilities approach to support delivery of person-centered care. Am J Bioeth. 2013; 13:29-39.
17. Morin E. Introduction à la pensée complexe. Paris: Seuil; 2005. See webpage on the internet: https://foundation.metaintegral.org/sites/ default/files/Complex_Thought_FINAL.pdf. Accessed February 26, 2016.

18. Reach G. Patients' nonadherence and doctors' clinical inertia: two faces of medical irrationality. Diabetes Manage. 2015;5:167-181.

19. Reach G. The Mental Mechanisms of Patient Adherence to Long-Term Therapies, Mind and Care, "Philosophy and Medicine". Foreword by Pascal Engel. Switzerland: Springer; 2015.

20. Reach G. Clinical Inertia, A Critique of Medical Reason. Forewords by Jon Elster and Joël Ménard. Switzerland: Springer; 2015.

21. Kahneman D, Tversky A. Prospect theory: an analysis of decision under risk. Econometrica. 1979;47:263-291.

22. Story GW, Vlaev I, Seymour B, Darzi A, Dolan RJ. Does temporal discounting explain unhealthy behavior? A systematic review and reinforcement learning perspective. Front Behav Neurosci. 2014;8:76.

23. Jones BA, Landes RD, Yi R, Bickel WK. Temporal horizon: modulation by smoking status and gender. Drug Alcohol Depend. 2009; 104(suppl 1):S87-S93.

24. Tversky A, Kahneman D. Judgment under Uncertainty: Heuristics and Biases. Science. 1974;185:1124-1131.

25. Kahneman D. Thinking, Fast and Slow. New York, NY: Farrar, Straus and Giroux; 2011.

26. Baumeister RF, Vohs KD, DeWall CN, Zhang L. How emotion shapes behavior: feedback, anticipation, and reflexion, rather than direct causation. Pers Soc Psychol Rev. 2007;11:167-203.

27. Croskerry P. From mindless to mindful practice - cognitive bias and clinical decision making. $N$ Engl J Med. 2013;368:2445-2448.

28. Summerskill WSM, Pope C. 'I saw the panic rise in her eyes, and evidence-based medicine went out of the door.' An exploratory qualitative study of the barriers to secondary prevention in the management of coronary heart disease. Fam Pract. 2002;19:605-610.

29. Stolper E, Van de Wiel M, Van Royen P, Van Bokhoven M, Van der Weijden T, Dinant GJ. Gut feelings as a third track in general practitioners' diagnostic reasoning. J Gen Intern Med. 2011;26: 197-203.

30. Gabbay J, le May A. Evidence based guidelines or collectively constructed "mindlines?" Ethnographic study of knowledge management in primary care. $B M J .2004 ; 329: 1013-1017$.

31. Dreyfus SE, Dreyfus HL. A five-stage model of the mental actvities involved in directed skill acquisition (1980). Bull Sci Technol Soc. 2004; 24:177-181

32. Guyatt G, Cairns J, Churchill D, et al. Evidence-based medicine. A new approach to teaching the practice of medicine. JAMA. 1992;268: 2420-2425.

33. Reach G. A psychophysical account of patient non-adherence to medical prescriptions. The case of insulin dose adjustment. Diabetes Metab. 2013;39:50-55.

34. Feinstein AR, Horwitz RL. Problems in the "evidence" of "evidencebased medicine". Am J Med. 1997;103:529-535.

35. Descombes V. The Mind's Provisions, a Critique of Positivism. Princeton: Princeton University Press; 2001:38-39.

36. Elster J. A plea for mechanisms. In: Hedstrøm P, Swedberg R, editors. Social Mechanisms: An Analytical Approach to Social Theory. Cambridge: Cambridge University Press; 1998:45-73.

37. Saarni SI, Gylling HA. Evidence based medicine guidelines: a solution to rationing or politics disguised as science? J Med Ethics. 2004; 30:171-175.

38. Schön DA. The Reflective Practitioner: How Professionals Think in Action. New York: Basic Books; 1983.

39. Frankfurt HG. Freedom of the will and the concept of a person. J Philos. 1971;68:5-20.

40. Dworkin G. The Theory and Practice of Autonomy. Cambridge: Cambridge University Press; 1988.

41. Lewis D. Dispositional theories of values. Proc Aristotelian Soc. 1989; 63:113-137.

42. Ricœur P. Oneself as Another. Chicago: The University of Chicago Press; 1992. [Translated by Kathleen Blamey] 
43. Parfit D. Reasons and Persons. Oxford: Oxford University Press; 2004.

44. Katz J. The Silent World of Doctor and Patient. New York, NY: The Free Press; 1984.

45. Emanuel EJ, Emanuel LL. Four models of the physician-patient relationship. JAMA. 1992;267:2221-2226.

46. Quill TE, Holloway RG. Evidence, preferences, recommendations finding the right balance in patient care. $N$ Engl J Med. 2012;366: 1653-1655.

47. Ubel PA. Medical facts versus value judgments - toward preferencesensitive guidelines. $N$ Engl J Med. 2015;372:1275-1277.

48. Thom DH; Stanford Trust Study Physicians. Physician behaviors that predict patient trust. Fam Pract. 2001;50:323-328.

49. Barrier PA, Li JT, Jensen NM. Two words to improve physician-patient communication: what else? Mayo Clin Proc. 2003;78:211-214.

50. Cabana MD, Rand CS, Powe NR, et al. Why don't physicians follow clinical practice guidelines? A framework for improvement. JAMA. 1999; 282:1458-1465.

51. Reach G. Patient autonomy in chronic care: solving a paradox. Patient Prefer Adherence. 2014;8:15-24.

52. Beauchamp TL, Childress JF. Principles of Biomedical Ethics. 7th ed. Oxford: Oxford University Press; 2012.

53. Cochrane AL. Effectiveness and Efficiency: Random Reflections on Health Services. London: Nuffield Provincial Hospitals Trust; 1972.

54. Miller LV, Goldstein J. More efficient care of diabetic patients in a county-hospital setting. $N$ Engl J Med. 1972;286:1388-1391.
55. Engel G. The need for a new medical model: a challenge for biomedicine. Science. 1977;196:129-136.

56. Kosecoff J, Kanouse DE, Rogers WH, McClosey L, Winslow CM, Brook RH. Effects of the National Institutes of Health Consensus Development Program on physician practice. JAMA. 1987;258:2708-2713.

57. Lomas J, Anderson GM, Domnick-Pierre K, Vayda E, Enkin MW, Hannah WJ. Do practice guidelines guide practice? The effect of a consensus statement on the practice of physicians. NEngl J Med. 1989; 9(321):1306-1311.

58. Inzucchi SE, Bergenstal RM, Buse JB, et al. Management of hyperglycemia in type 2 diabetes: a patient-centered approach. Position statement of the American Diabetes Association (ADA) and the European Association for the Study of Diabetes (EASD). Diabetologia. 2012;55:1577-1596; Diabetes Care. 2012;35:1364-1379.

59. Reach G. Clinical inertia, uncertainty and individualised guidelines. Diabetes Metab. 2014;40:241-245.

60. Sackett DL, Rosenberg WM, Gray JA, Haynes RB, Richardson WS. Evidence based medicine: what it is and what it isn't. BMJ. 1996; 312:71-72.

61. Haynes B, Haines A. Getting research findings into practice. Barriers and bridges to evidence based clinical practice. BMJ. 1998;317:273-276.

62. Kon AA. The shared decision-making continuum. JAMA. 2010;304: 903-904.

63. Reach G. Patient education, nudge and manipulation: defining the ethical conditions of the person-centered model of care. Patient Prefer Adherence. 2016;10:459-468.
Patient Preference and Adherence

\section{Publish your work in this journal}

Patient Preference and Adherence is an international, peer-reviewed, open access journal that focuses on the growing importance of patient preference and adherence throughout the therapeutic continuum. Patient satisfaction, acceptability, quality of life, compliance, persistence and their role in developing new therapeutic modalities and compounds to optimize

\section{Dovepress}

clinical outcomes for existing disease states are major areas of interest for the journal. This journal has been accepted for indexing on PubMed Central. The manuscript management system is completely online and includes a very quick and fair peer-review system, which is all easy to use. Visit http://www. dovepress.com/testimonials.php to read real quotes from published authors. 